\title{
Subjective Tests for Vestibular Dysfunction
}

\section{Basic Advantages}
a) Well established - criteria for diagnostic testing
b) Insights into site of lesion
c) Alerts the examiner
d) High specificity

\section{Basic Disadvantages}
a) Require New and improvised versions of test
b) Not well supported for diagnosing
c) Low sensitivity
d) Requires objective tests to support findings

\section{Subjective Visual Vertical test}

Given By-Bohmer A, Rickenmann J [1].

SVV is an estimation technique whereby a subject adjusts a visible luminescent line, while seated in complete darkness, to what they consider to be upright or true vertical.

\section{Principle}

SVV or SVH as measured in the upright position is influenced by the utricles, saccules and horizontal semicircular canals.

\section{Purpose}

a) To assess utricular function

b) central connections, including superior vestibular nerve.

c) To assess the degree of ocular torsion

\section{Procedure}

a) Subject is made to sit in a dark room.

b) Individual is asked to align a luminous bar with a position that the individual judges to be vertical

c) 10 trials are given before the mean and standard deviations of the offset from true vertical are determined.

\section{Results}

A. Normal: 2 degrees tilt is considered to be able to set the SVV correctly when the light bar has an initial inclination relatively parallel to the body axis.

B. Abnormal: More than 2 degrees tilt indicates the peripheral problem that is ipsilateral and offset is towards the same side.

\section{Indications}

a) Brandt and Dietrich [2] found that pontomedullary lesions produce ipsiversive tilts (deviation of subjective visual vertical toward the side of the lesion), Pontomesencephalic lesions produce contraversive tilts (away from the lesion). The deviations accompanied by the ocular tilt reaction.

b) Disruption of both the otolithic and vertical semicircular canal pathways are thought to be involved in the deviations.

c) Thalamic lesions may produce either ipsiversive or contraversive tilts of subjective visual vertical. Lesions of the parietoinsular vestibular cortex tend to produce contraversive deviations. Lesions at the level of the thalamus and above will not produce an accompanying ocular tilt reaction.

d) Lesions in the inner ear also produce deviation of subjective visual vertical due to differences in the tonic output from the otolithic organs in the inner ear [3].

e) Abnormal in headache sufferers, particularly those with migraine.

\section{Limitations}

a) Bilateral utricular defects are not assessed Findings to be supported with other tests Sensitivity and specificity questionable

b) Inability to properly estimate the true vertical when the light bar was initially inclined in the opposite direction

c) SVV is subject to variation over time, due to central compensation

\section{Fukuda Stepping Test}

Given By Fukuda [4]

Persons with unilateral peripheral vestibular dysfunction would turn to the side of lesion

History- middle ear pathology can influence results of caloric stimulation due to alteration of thermal conductivity across middle ear space.

\section{Principle}

a) Body rotation results from the unbalanced static activity of the two end organs 
b) Imbalance in the yaw ear is interpreted centrally as rotation plane towards the contra-lesioned

c) Deviation of body occurs towards the ipsi-lesioned side.

\section{Purpose}

a) Used to assess peripheral VS impairment manifested as asymmetry in lower extremity vestibulospinal reflex tone
b) Labyrinthine dysfunction
c) Indicates possible acoustic neuroma.

\section{Procedure}

a) With the arms extended at a $90^{\circ}$ angle in front of the body and the eyes closed, the patient marches in place for 50 steps.

b) Stepping rate -110 steps per minute.

c) The angle, direction, and distance of deviation from the origin should be recorded.

d) It is helpful to make use of a reference mark system such as a band of tape on the floor oriented along the sagittal plane at the start of the test or a thin, dense rubber mat with a polar pattern marked on it

\section{Results}

A. Normal: 50 steps without significant angular deviation from the starting position (i.e., normal rotation $\leq$ $30^{\circ}$ ).

B. Abnormal: A rotation of greater than 45 degrees in either direction is considered to be abnormal. [4,5].

\section{Advantages}

a) Useful test for peripheral VS lesion

b) Reveals deficits of VSR compensation when VOR compensation is complete.

c) A useful screening tool

\section{Limitations}

a) FST with and without head shake component is not a reliable screening tool for peripheral vestibular asymmetry in chronic dizzy patients

b) Reliability of predicting imbalance of the labyrinthine system based on the poor reliability scores- questionable

c) Not reliable for lateralization and localization of lesion

d) Limited use in spontaneous nystagmus cases

Past pointing and falling test

a) Past-pointing is considered to be a sign of tonic imbalance in the output of the peripheral vestibular system.

b) Given By Barany in 1910( Related articles in German)

c) The past-pointing test was one of the first attempts to clinically assess vestibular functions.

d) The past pointing falling and slow component of nystagmus are in the same direction.

I. Acute VS failure-nystagmus on the opposite side but past pointing and slow component on ipsilateral side

e) Past pointing occurs on same side of target and will occur with either limb

I. Both limbs- vestibulopathy

\section{Principle}

a) Asymmetric tonic signals from afferent system manifested as a relative abundance of activity from intact end organ

b) Compensatory VSR elicited in order to maintain position. Hence body rotates towards the lesioned organ, resulting in past pointing.

\section{Purpose}

a) Used to assess tonic imbalance in the output of the peripheral vestibular system

b) Test for defective functioning of the vestibular nerve

c) Indicative of cerebellar signs

d) Used for assessing vestibulospinal pathways.

\section{Procedure}

The patient is instructed to extend the arms and place the index finger of one hand on the index finger of the examiner or a static target. Eyes are then closed and arms raised above head and quickly returned to the perceived starting position

\section{Results}

A. Normal: finger returns to the starting point with little lateral deviation

B. Abnormal: The patient's hand will drift away from the target as the trunk rotates.

i. Peripheral VS lesion: deviation to one side and compensated peripheral weakness in case of less consistent case.

\section{Advantages}

a) Detects acute lesions

b) Gives insight about compensated and decompensated lesions

\section{Limitations}

a) Not reliable in case of chronic vestibulopathy after 
compensation has occurred

b) Repeated testing produces variable results No lateralization information

c) Low sensitivity

d) Cannot detect compensated vestibular lesions

\section{Vertical writing}

a) Variant of past- pointing

b) Described by Fukuda-1959 [4]

c) Deviation tendency is due to relative difference in afferent vestibular input to the brainstem

\section{Procedure}

Patients instructed to write a series of characters or symbols in vertical direction on a piece of paper. With eyes open and then with eyes closed.

\section{Results}

a) Eyes open- Normals and Vestibular patients-vertical line of characters

b) Eyes closed- Unilateral Peripheral lesions-slanting and deviation to the side of lesion

c) Central overcompensation of unilateral peripheral vestibular impairment-opposite side of lesion

\section{Limitation}

a) Cannot only conclude as Vestibular site of lesion

b) Some mild otologic disorders-otitis media-similar finding

\section{Romberg Test}

a) First described by Moritz Heinrich von Romberg who found that patients with tabes dorsalis (neurosyphilis) often complained of increased unsteadiness in the dark.

b) The test should be performed in all patients who complain of dizziness, imbalance or falls to rule out sensory ataxia

c) Romberg's test is a test of the proprioception receptors and pathways function.

\section{Romberg sign}

The Romberg sign demonstrates loss of postural control in the absence of visual input suggestive of proprioceptive deficit in the lower limbs as a result of severely compromised proprioception.

\section{Principle}

a) The physiology behind this test is that to maintain balance we need at least 2 of the following 3 components: vision, proprioception and vestibular function.

b) Vestibular problem -eyes open balance maintained

c) Eyes closed-only proprioception insufficient to maintain balance

d) Only propioreception- eyes closed - improper VS functioning

\section{Purpose}

a) Identifies imbalance in the vestibulospinal reflex due to tonic imbalance in peripheral vestibular system

b) To assess the integrity of the dorsal columns of the spinal cord.

\section{Procedure}

The patient is asked to stand with feet together and arms by side with eyes first opened and then closed.

\section{Results}
a) Open eyes -imbalance compensated
b) Closed eyes- relative reduction of vestibular input to cerebellum
c) With eyes open poor balance -cerebellar ataxia.
d) Eyes closed- problem in vestibular or proprioceptive systems.
e) Peripheral lesion- patient sways to side of lesion
f) Central lesion- Instability
g) Bilateral or Unilateral Peripheral VS lesion- Negative (Table 1).

\section{Indications}

a) Vitamin B12 deficiency - Subacute combined degeneration of the cord,

b) Diabetic peripheral large fibre neuropathy,

c) Friedrich's ataxia,

d) Tabes dorsalis

Table 1: Sensary Inputs.

\begin{tabular}{|c|c|c|}
\hline Test Condition & Description & Sensory inputs \\
\hline Eyes open & firm surface & $\begin{array}{c}\text { Visual, } \\
\text { proprioceptive, } \\
\text { vestibular }\end{array}$ \\
\hline Eyes closed & firm surface & $\begin{array}{c}\text { Proprioceptive, } \\
\text { vestibular }\end{array}$ \\
\hline Eyes open & compliant surface & Visual, vestibular \\
\hline Eyes closed & compliant surface & Vestibular only \\
\hline
\end{tabular}

\section{Advantage}

a) Differentiates between Peripheral VS disorder and propioreceptive anomalies 
b) Differentiates between patients with muscle Advantage

weakness from dorsal column disease

\section{Limitations}

a) Often misunderstood with cerebellar signs

b) There is still no standard approach to applying the Romberg test in clinical neurology

c) The criteria for and interpretation of an abnormal result continue to be debated.

d) Limited studies available that define its reliability and validity.

e) Data statistically showing its effectiveness is not readily available.

f) Insensitive to compensated vestibular lesions

g) Useful in assessment of dorsal column but not vestibular system

h) Cannot distinguish patients with cerebellar lesions and propioreceptive lesions

i) Sometimes cannot identify normals and patients with peripheral lesions

\section{Sharpened Romberg test}

a) A variation of the Romberg Test,

b) Consists of support by position narrowing the patient's base of placing feet in a heel to toe

c) Given by Furman \& Cass, 2003 [5]

\section{Principle}

a) Propioreceptive input from ankle joints becomes discordant relative to vestibular and visual input.

b) Only vestibular input can be used to help maintain the upright position

\section{Purpose}

To identify vestibular impairment

\section{Procedure}

a) In this, the patient stands with one heel in front of toes and arms folded across chest

b) Test instructions do not specify which foot, preferred or non-preferred, should be placed in front of the other.

c) $\quad 2^{\text {nd }}$ method- The patient should be instructed to keep hands on hips for the whole 30 seconds. If the patient takes a step or removes hands from hips, the timer is stopped and the patient may attempt the test one more time.

\section{Results}

Inability indicates vestibular impairment a) This test is useful for assessing ataxia in mild mountain sickness

b) Helpful in diving test

c) Widely used in Naval force

d) Provides baseline for dysfunction

\section{Limitations}

The sharpened Romberg does have an early learning effect that will plateau between the third and fourth attempts.

Patients who perform the test during several trials may begin to adapt and perform better on each successive trial. This could skew the results and provide an inconclusive result

\section{Gait testing}

An individual's gait is defined as his or her method of walking.

\section{Types of gait}

a) A tandem gait test is one where the individual has to walk heel to toe.

b) Incordination indicative of ataxia and difficulty in motor movements

c) Used in Drunken driving test

d) The Tinetti gait test is used for elderly individuals. As people age, they tend to lose their absolute control over mobility and the precision of their mobility.

e) The Tinetti gait test is also used to establish parameters related to the balance of the individual.

f) Inability to perform- balance disorder

\section{Purpose}

To identify peripheral lesions

\section{Principle}

Gait involves multiple sensory and motor systems. These include vision, proprioception, lower motor neurons, upper motor neurons, basal ganglia, the cerebellum, and higherorder motor planning systems in the association cortex.

\section{Procedure}

The patient is asked to walk along a straight line to a fixed point, first with eyes opened and then eyes closed

\section{Results}

Peripheral VS lesion- patient deviates to the affected side

\section{Advantages}

a) Very simple and rapid test

b) Does not require prior preparation of the subject 


\section{Limitation}

a) Cannot identify central lesions

b) Cannot identify person with underlying vestibular disorder when the person is intoxicated

Unterberger test

a) Siegfried Unterberger (1939)

b) Method similar to Fukuda test

c) The differences and controversies explained by Grommes C, and Conway D, (2011) in the Journal of Historical Neurosciences

\section{Purpose}

a) Identifies labyrinthine dysfunction

b) Assess unilateral peripheral Vestibular disturbances.

\section{Procedure}

The patient is asked to match up and down the spot with eyes closed and hands clasped at arm length in front of them.

\section{Results}

A. Normal: Less tendency to deviate from left to right. A turn up to 45 degrees for every 50 steps is normal

B. Abnormal: Rotational movement towards the side of lesion

I. Deviation to either of the side depending on the lesion: Peripheral VS lesion

II. Turning in various direction: Cerebellar lesions

\section{Limitations}

a) The value of this test is questionable in the view of multiplicity of the factors that influence the response

b) Reliability questionable in case of compensated vestibular dysfunction

c) The balance disorder caused by non vertigous causes not differentiated

d) Cannot identify bilateral lesions

e) Cannot identify central vestibular pathology

\section{Head thrust test}

a) Halmagyi and Curthoys in 1988 [6]

b) The HTT, which is based on the the doll's eye phenomenon, is used to evaluate the vestibular-ocular reflex (VOR) in the horizontal plane

c) To demonstrate the VOR, the patient moves his or her head from side to side while focusing on a midline target.

d) This causes the eyes to move in a velocity like that of the head movement but in the opposite direction.

\section{Purpose}

a) Used to evaluate unilateral vestibular function To assess chronic vestibular loss [7-12]

b) To identify the side of the hypo functioning labyrinth.

\section{Procedure}

The patient's head is turned 15-30 degrees from the centre and then rapidly rotated to the other side with patient focussing on the examiner's eyes

\section{Results}

a) Patients with unilateral vestibular weakness will have a catch-up saccade when rotated rapidly to the side of the lesion

b) Complete loss of peripheral vestibular functionPositive

c) Mild loss indicated by low excitability differences between sides on the ENG caloric test - negative

d) Unilateral hearing loss- positive- acoustic neuroma.

e) Chronic peripheral loss- central compensation that appears within the first few days after an acute vestibular insult such as vestibular neuronitis, labyrinthitis, or skull base fractures [13-17].

\section{Limitation}

Sensitivity is lower (35\%-39\%) for patients with nonsurgically induced unilateral vestibular hypofunction

a) Orthostatic hypotension

Orthostatic hypotension is a reduction of systolic blood pressure of at least $20 \mathrm{~mm} \mathrm{Hg}$ or diastolic blood pressure of at least $10 \mathrm{~mm} \mathrm{Hg}$ within three minutes of standing

b) P.C. Rowe and J. Bou-Holalgah (1995)

c) Dr. David Streeten was called the «father of or thostatic hypotension»

d) Orthostatic hypotension is defined as a fall in systolic blood pressure of at least $20 \mathrm{mmHg}$ and/or in the diastolic blood pressure of at least $10 \mathrm{mmHg}$ between the supine reading and the upright reading [18-26].

\section{Purpose}

To differentiate between true vertigo and non vertigo

\section{Assessment}

\section{A. Tilt table test}

a) A tilt table test, occasionally called upright tilt testing Dysautonomia or syncope

b) Dizziness 
c) Lightheadedness, with or without a loss of Limitations

consciousness

d) Positional tachycardia [27-35].

\section{Procedure}

a) The patient will be strapped to a tilt table lying flat and then tilted or suspended completely or almost completely upright (as if standing).

b) Most of the time, the patient is suspended at an angle of 60 to 80 degrees.

c) The test either ends when the patient faints or develops other significant symptoms, or after a set period (usually from 20 to 45 minutes, depending on the facility or individualized protocol).

d) Sometimes, the patient will be given a drug, such as Glyceryl trinitrate or isoproterenol, to create further susceptibility to the test.

e) Symptoms, blood pressure, pulse, electrocardiogram, and sometimes blood oxygen saturation are recorded.

\section{Result}

This drop in BP indicates the presence of light-headedness and non- vertigo disease

\section{Dysdiadochokinesis testing}

a) Inability to perform rapidly alternating movements, such as rhythmically tapping the fingers on the knee.

b) Cause-cerebellar lesion and is related to dysmetria, which also involves inappropriate timing of muscle activity.

\section{Purpose}

Used to assess cerebellar lesions

\section{Procedure}

Patients are asked to slap knees with palm and dorsum of hand rapidly and alternately the clinician is expected to be very vigilant and experienced [36-45].

\section{Result}

Inappropriate timing of muscle activity. This is visibly apparent when attempting to perform rapid alternating movement require efficient initiation and cessation

\section{Advantages}

a) Provides insight into cerebellar lesions Rules out cerebellar ataxia

b) Identifies vertigo and dysequilibrium due to neurodegerative disorder such as Freidreich's ataxia and Multiple sclerosis

c) Helps suspect as having multiple sclerosis in undiagnosed patients
a) An exclusive test to identify central vestibular lesion
b) Cannot identify peripheral vestibular lesions [46-50].

\section{Spontaneous nystagmus}

a) Nystagmus is an important sign in the evaluation of vestibular system.

b) It is defined as involuntary, rhythmical, oscillatory movement of eyes (Table 2).

Table 2: Degree of Nystagmus.

\begin{tabular}{|c|c|}
\hline \multicolumn{2}{|c|}{ Degree of Nystagmus } \\
\hline $1^{\text {st }}$ degree & $\begin{array}{c}\text { It is weak nystagmus and is present } \\
\text { when patient looks in the direction of } \\
\text { fast component. }\end{array}$ \\
\hline $2^{\text {nd }}$ degree & $\begin{array}{r}\text { It is stronger than the 1st degree } \\
\text { nystagmus and is present when patient } \\
\text { looks straight ahead. }\end{array}$ \\
\hline $3^{\text {rd }}$ degree & $\begin{array}{r}\text { It is stronger than } 2 \text { nd degree } \\
\text { nystagmus and is present even when } \\
\text { patient looks in the direction of the slow } \\
\text { component. }\end{array}$ \\
\hline
\end{tabular}

\section{Purpose}

To identify underlying organic lesion

\section{Principle}

a) SN occurs when the unilateral peripheral VS or VIIIth nerve is affected because of reduced neural firing which decreases in that side and the other side remains intact.

b) This asymmetry $b / w$ the two end organs generates the illusion of rotatory motion in the absence of head movement.

c) Best identified before VS compensation occurs.

\section{Procedure}

a) Patient is seated in front of the examiner or lies supine on the bed.

b) The examiner keeps his finger about $30 \mathrm{~cm}$ from the patient's eye in the central position and moves it to the right or left, up or down but not moving more than 30 degrees from the central position

c) Test to be repeated by using non visual fixationsfrenzel's lenses or dark room + patient vaguely staring into the distance when instructed to look to left and then to right.

d) This is done to check the intensity of nystagmus [5052].

\section{Results}

a) Irritative lesion of the labyrinth-nystagmus to side of lesion, 
b) Paretic lesion- nystagmus to the healthy side,

c) central lesion- nystagmus is vertical rotatory, dysconjugate, monocular.

d) Arnold chairi malformation- A down beating vertical nystagmus .

e) Peripheral vertigo- same direction nystagmus even if the gaze is changed. It increases with visual fixation removed.

f) Central vertigo- direction of nystagmus can change the direction when looking in opposite direction and is unaltered even if visual fixation is removed

g) Vestibular nystagmus (peripheral type) lesion of labyrinth VIIIth nerve [25-26]

h) Vestibular nystagmus (central type), lesion in the central neural pathways (vestibular nuclei, brainstem, cerebellum).

\section{Advantage}

Best results obtained soon after VS damage

\section{Limitation}

a) Cannot diagnose end organ disorder

b) SN cannot be observed after a few days

c) Cannot be used as bedside evaluation to diagnose unilateral vestibular dysfunction without quantitative testing $[53,54]$

d) Degree and site of impairment from the direction of SN cannot be determined due to inter-subject variability and quality of central compensation

e) Only the presence or absence of spontaneous nystagmus to diagnose unilateral peripheral VS hypofunction is unacceptable.

f) For UVH sensitivity-less than $50 \%$

g) In case of organic VS disorder the finding should be supported with quantitative findings

\section{Head shake nystagmus}

a) First described in 1907 by Robert Bárány (1907).

b) Head-shaking nystagmus (HSN) is a jerk nystagmus that may follow a prolonged sinusoidal head oscillation.

c) Early test-Boertes (1923)

d) Contemprorary test- Kamei and Kornhuber (1964)

\section{Principle}

A clinical test that looks for nystagmus that appears after vigorous horizontal (horizontal SCC) head shaking for about 15 seconds at a frequency of $2 \mathrm{~Hz}$. The test is a high-frequency vestibular stimulus [55-60]

\section{Purpose}
a) Evaluates symmetry in VOR b) Evaluation for a peripheral vestibular system
disorder.

\section{Procedure}

a) Head is shaken vigorously for 10-30 cycles and then stopped.

b) The patient is asked to tilt his or her own head down 30 degrees to allow maximum stimulation of the horizontal canal and told to shake head back and forth rapidly as quickly as possible for 30 seconds [30-32].

c) Open eyes and observe nystagmus after stopping

\section{Patterns of HSN}

A. Peripheral

a) Primary phase beats away from paretic ear

b) Secondary phase is universal but weak

c) Horizontal HS- no or little vertical nystagmus

d) Vertical HS- elicits nystagmus which may beat towards paretic ear

e) Nystagmus may not appear except for prolonged and powerful head shaking

\section{B. Central}

a) Direction of nystagmus not well correlated with the side of lesion
b) Secondary phase- may be as big as primary phase
c) Nystagmus is cross coupled
d) Nystagmus may appear afer 1-2 head shakes

\section{Results}

a) Transient vestibular nystagmus- peripheral and central VS lesion

b) Unilateral VS dysfunction - unopposed stimulation of intact labyrinth resulting in slow phase to side of the lesion and a rapid nystagmus to intact side.

c) Vertical nystagmus-cerebellar dysfunction

d) Head shake nystagmus- peripheral vestibular dysfunction and cerebellar dysfunction.

\section{Advantage}

Good screening tool for universal vestibular dysfunction

\section{Limitation}

a) Sensitivity - poor Unreliable screening test. 
Specificity- poor

b) Poor predictor for moderate to low level of vestibular hypofunction

c) No criterion present that indicates how much loss is needed for a positive HSN test

\section{Dynamic visual acuity}

a) VOR helps stabilizing gaze during head movement. This vestibular driven reflex process allows the observer to retain visual acuity with head movement. This is dynamic visual acuity.

b) Given by Miller and Ludvigh (1962) [37]

c) Initial test- Oscillopsia test used to quantify the performance of DVA

\section{Purpose}

Used to evaluate bilateral vestibular weakness

\section{Procedure}

Baseline visual acuity is taken and then the same task using snellen's chart, the patient is asked to read by rotating the head back and forth at $1-2 \mathrm{~Hz}$ rate.

\section{Results}

a) Normal- Loss of one line

b) Loss of 2-3 lines suggests vestibular weakness.

c) This test should be abnormal in patients with bilateral vestibular weakness and can be used to diagnose these challenging patients.

\section{Advantages}

a) Availability of computerized system of DVA

b) DVA testing during imposed head motion isa a quantitative and clinically feasible measure that reflects functionally significant abnormal VOR.

\section{Disadvantages}

a) Cannot be tested in patients in case of absence of corrected vision

b) The system for assessment is not widely available

c) Standard protocol for the system used is not available

d) Varied results and inconsistent findings [40]

\section{Why varied results and inconsistent findings????}

a) Differences in methodology

b) Variability in the frequency of subject's head movement

c) Variation in the method to calculate DVA scores

d) Variation in the degree of vestibular system compensation in patients with unilateral vestibular hypofunction

e) Best performed by experienced clinician

Modified clinical test for sensory interaction of balance

a) The Modified Clinical Test of Sensory Interaction and Balance CTSIB is an accepted test protocol for Balance assessment on a static surface

b) Postural balance involves special sensory receptors that provide information in regards to various environmental and physiological conditions that may affect a person's ability to maintain equilibrium.

\section{Purpose}

a) Used to assess the integrity of sensory system.

b) Functional compensation with respect to stance is obtained

c) Assesses patient's balance under a variety of conditions to infer the source of instability

\section{Principle}

a) Maintaining postural balance involves complex coordination and integration of multiple sensory, motor and biomechanical components

b) The test progressively reduces the sensory input system available to the patient for maintaining quiet stance. By 4th condition, only VS is available to provide accurate information about the body's position and movement.

\section{Procedure}

Here, the patient's ability to maintain quiet volititional stance is evaluated as they sequentially stand on
a) A flat firm
b) A flat firm
i. $\quad$ surface with eyes opened
ii. surface with eyes closed
c) A compressible surface with eyes opened
d) A compressible surface with eyes closed

\section{Result}

Inability to maintain postural control during the testing indicates that the sensory system is dysfunctioning

\section{Advantages}

a) The breadth of the existing studies supporting and accepting the CTSIB as a valid clinical assessment of balance.

b) Well documented definitive correlations for mild 
traumatic brain injury.

c) The comprehensiveness of the test to address each of the systems that contributes to balance: Visual, vestibular and somotosensory.

d) Ease and efficiency of doing the test and high inter and intra rater reliability.

e) Clinician familiarity with the test.

\section{Hyperventilation induced nystagmus}

a) Thought to be of psychiatric manifestation

b) Hyperventilation can either activate a latent nystagmus in central or peripheral vestibular diseases or it can interact with a spontaneous nystagmus, by reducing it or increasing it.

\section{Principle}

During rapid periods of ventilation, the conduction velocity of a demyelinated nerve can be transiently increased thereby creating a situation where the affected ear will present as being hyperfunctional compared to the «normal» ear. Therefore, the nystagmus commonly beats towards the side of dysfunction.

\section{Purpose}

a) Used to assess the integrity of entire vestibular system.

b) Differential diagnosis of patients with psychosomatic and anxiety related disorders

c) Assessing demyelinating conditions Used to assess vestibular end organs

\section{Procedure}

Frenzel lenses or light occluding VNG goggles are worn. In standing, the patient is asked to take rapid and deep breath for 30-60sec. The examiner should observe eyes before hyperventilation and swaying of the patient.

\section{Results}

Non nystagmus and slight sensation of light headedness or dizziness appears. A sway in saggital plane

\section{Indications}

a) Nystagmus in horizontal plane for $60 \mathrm{sec}$ or moreincomplete unilateral peripheral lesion.

b) Ipsi-lesion- Fast phase nystagmus.

c) Complete unilateral peripheral lesioncontralateral lesional beating nystagmus. Also indicates bilateral incomplete lesions and central lesions but the direction is unpredictable

d) cerebellar lesion- slow phase velocity of down beating nystagmus

\section{Advantages}

a) High sensitivity

b) Indicates site of lesion

\section{Limitations}

a) Little localizing value less specificity

b) Should be supported with other diagnostic tests

\section{Ocular tilt reaction/ skew deviation}

a) Given by Hertwig

b) Occurs due to imbalance of utriculocular reflex

c) Ocular tilt is considered as a combination of vestibulocular and vestibulospinal anomalies resulting in vertical misalignment of the eyes, head tilt towards the lower eye and ocular torsion towards the lower eye [57-60]

\section{Purpose}

a) Used to assess conjugate movements of the eyes.

b) The type and direction of skew can provide information valuable to the determination of the site of lesion.

\section{Principle}

a) The primate oculomotor system produces predominantly conjugate movements of the eyes; thus variation from this pattern are considered pathologic.

b) One such variation is characterized by the presence of a vertical misalignment caused by an imbalance of the vestibule-ocular reflex and referred to as "Skew deviation". When accompanied by head tilt in the roll plane and ocular torsion, the traid of symptoms is referred to as "ocular tilt reaction".

\section{Procedure}

a) An examination of static visual alignment should be performed when the patient maintains gaze in the primary or straight-ahead position. The examiner should look for the presence of a vertical skew deviation where one eye demonstrates an abnormal vertical orientation relative to the other. The examiner should also be alert for the presence of a head tilt of 10 to 30 degrees toward the site of lesion and ocular-torsion toward the lower eye [12-20].

\section{Results}

a) Normal: Careful observation of the patient will reveal normal horizontal, conjugate eye position with gaze direction directed straight ahead and vertical head alignment. The examiner should be careful to differentiate between facial asymmetries and the presence of a skew deviation or ocular tilt reaction.

b) Abnormal: The examiner will note the presence of a vertical misalignment of the eyes from the normal horizontal 
gaze position. The patient may also exhibit head tilt of 10 to 30 degrees toward the side of the lower eye $[15,18]$.

\section{Indications}

a) Lesions of utricular nerve or at level of vestbular nulei- ipsilateral ocular tilt reaction

b) Lesions above the level of vestibular nuclei (due to decussation of fibers)-contralateral ocular tilt reaction.

\section{Limitation}

Requires supplementary tests for supporting the findings Valsalva Induced nystagmus

a) Self induced change in middle ear and intracranial pressure is called valsava manaeuver

b) Causes eye movements in patients with craniocervical junction abnormalities and disorders affecting inner ear.

c) Given by Antonio Mario Valsalva (1666-1723)

d) Hennerbert identified eye movements in valsalva manaeuver

\section{Hennerbert sign}

a) Describes conjugate eye movement away from the affected ear with positive pressure applied to the EAM

b) A movement towards the affected ear is expected with negative pressure

c) The presence of such movement allows the examiner to deduce the presence of anomalous connection $b / w$ the inner ear and the external environment $[20,45]$.

\section{Principle}

a) Increased pressure in the middle ear acts as an abnormal connection b/w labyrinth and external environment to induce pressure gradient in the cochlea

b) Increased pressure within the affected labyrinth stimulates neural firing by displacing the cupula of the semicircular canal.

c) Increased neural discharge rate drives the VOR such that a compensatory eye movement away from the affected ear is generated.

d) In case of straining against a closed glottis, increased pressure within the middle ear fossa is generated through changes in the central venous pressure.

e) Increasing and maintaining pressure within the thoracic cavity decreases venous return through the jugular vein thereby raising intracranial pressure.

f) An abnormal connection $b / w$ the middle ear fossa and the vestibular labyrinth will induce a pressure change in the affected canal and elicit downbeating torsional nystagmus towards the affected side

\section{Procedure}

A. Method 1

a) Increase air pressure in the sinuses and middle ear by taking deep breath.

b) Pinch nose, close mouth then tightly blow.

c) The patient should maintain pressure for 10-15 seconds

BMethod 2

a) Increasing venous pressure by asking the patient to strain against the closed glottis and lips for $10-15 \mathrm{sec}$, as if, pressurizing the lungs to help stabilize the trunk while lifting weight.

\section{Results}

A. Normal-VM should not elicit sensation of dizziness or vertigo

a) Careful observation to identify shift of the eyes (positive Hennerbert sign)

b) No elicited conjugate eye movement should be observed under frenzel or VNG google [50]

B.Abnormal results

a) Increased ME or intracranial pressure as a result of either variant of valsalva manaever will elicit a conjugate movement of eyes towards the contra-lesioned ear in case of lateral and anterior canal involvement.

b) Increased intacranial pressure- corrective saccadenystagmus towards ipsilateral ear

c) Direction of fast phase nystagmus- site of lesion

d) Torsional and downbeating vertical nystagmus indicate site of lesion in anterior canal

e) Vertical upbeating nystagmus with torsional component suggest involvelemnt of posterior canal

f) Direction of torsion provides information about laterality of the lesion

g) Dehiscence of posterior canal will elicit upbeating and torsional nystagmus with fast phase oriented towards the affected ear.

h) The fast phase of torsional nystagmus will beat in a clockwise direction for lesions of the left ear and counter clockwise for lesions in the right ear.

i) Horizontal nystagmus- involvement of lateral SCCbeating affected towards the ear

\section{Advantages}

Useful screening test Good Sensitivity 


\section{Limitation}

a) Cannot distinguish b/w nystagmus due to VS disorder and ME disease

b) Not useful in the presence of upper respiratory infection $[23,25]$

\section{Hallpike Manaeuver (positional test)}
a) Dix and Hallpike, 1952
b) Mostly used to assess BPPV

\section{Purpose}

a) Used to differentiate peripheral from central lesion.

b) Identifying vertigo in certain head positions

\section{Procedure}

a) Patient sits on a couch. Examiner holds the patients head, turns it $45^{\circ}$ to the right and then places the patient in a supine position so that his head hangs $30^{\circ}$ below the horizontal. Patient's eyes are observed for nystagmus. The test is repeated with head turned to left and then again in straight head-hanging position [30]

\section{Results}

a) In centrallesions (tumors of IVth ventricle, cerebellum, temporal lobe, multiple sclerosis, vertibrobasilar insufficiency or raised intracranial tension) nystagmus is produced immediately, as soon as the head is in critical position.

b) Direction of nystagmus also varies in different test positions (direction changing) and is non-fatiguable on repetition of test.

c) In benign paroxysmal positional vertigo, nystagmus appears after a latent period of 2-20 seconds, lasts for less than a minute and is always in one direction, i.e. towards the ear that is undermost.

d) On repetition of the test, nystagmus may still be elicited but lasts for a shorter period.

e) On subsequent repetitions it disappears altogether, i.e. nystagmus is fatiguable.

f) If the test is negative, central nervous system involvement should be considered.

\section{Advantages}

a) Although there are alternative methods to administering the test, Cohen proposes advantages to the classic maneuver.

b) The test can be easily administered by a single examiner, which prevents the need for external aid.

c) Due to the position of the subject and the examiner, nystagmus, if present, can be observed directly by the examiner.

\section{Limitations}

a) The sensitivity of this test is not $100 \%$. Some patients with a history of BPPV will not have a positive test result.

b) Specificity $-75 \%$.

c) The test may need to be performed more than once as it is not always easy to demonstrate observable nystagmus that is typical of BPPV [55-60].

d) Patients may be too tense, for fear of producing vertigo symptoms, which can prevent the necessary brisk passive movements for the test.

e) A subject must have adequate cervical spine range of motion to allow neck extension, as well as trunk and hip range of motion to lie supine. Cannot be used in case musculoskeletal and obesity issues in a subject.

\section{Modified Dix- Hallpike position}

a) Gans and Harrington-2002

b) Modified version of Dix- Hallpike positional test

\section{Procedure}

a) The examiner stands behind the patient. The patient turns the head slightly toward the test ear, and the examiner supports the patient's neck and back while the patient is lowered into the provoking supine position with the neck slightly hyper extended and off. Once in the supine position, the examiner has a clear view of the patient's eyes. Because the provocation of symptoms is gravity based and due to changing positions of the involved posterior canal, rapid positioning is not required.

\section{Results}

a) If the response is determined to be classic, a benign peripheral vestibular lesion in the undermost ear is suspected.

b) If the response is "non classical" (one or more of the above conditions are absent), the lesion can be either peripheral or central.

c) If rotatory nystagmus, is observed, the results must have the following 4 characteristics to be considered classically positive.

d) Delayed onset- Need to observe patient at least for 20 second

e) Transient burst of nystagmus- last about $10-15 \mathrm{sec}$

f) Subjective report of vertigo

g) Fatigability 


\section{Eye movement test}

Eye movement (ocular motility) is the voluntary or involuntary movement of the eyes, helping in acquiring, fixating and tracking visual stimuli. It may also compensate for a body movement, such as when moving the head.

\section{Purpose}

To assess voluntary control of eye movement Useful in assessing nystagmus

\section{Principle}

a) A normally functioning vestibular system exhibits voluntary control of eye movement.

b) It also tends to stabilize gaze during head movement

\section{Procedure}

a) Saccade tracking is assessed by having the patient quickly shift gaze from one point to another, typically the examiner's nose and a finger held to side (Videos 20-23)

\section{Result}

a) Assymmetric or grossly abnormal responses indicate the possibility of cerebellar dysfunction

b) Beating movements- indicates nystagmus

\section{Advantage}

a) Quick and rapid test

b) Provides basic information about Vestibular functioning

\section{Limitations}

a) Accuracy, speed and initiation time should be judged.

b) Age medication and inattention influences the activity.

c) Cannot distinguish between eye movemnt disturbances due to improper vestibular functioning or opthalmic disorder

\section{References}

1. Böhmer A, Rickenmann J (1995) The subjective visual vertical as a clinical parameter of vestibular function in peripheral vestibular disease. J Vestib Res 5(1): 35-45.

2. Dieterich M, Brandt T (1993) Ocular torsion and tilt of the subjective visual vertical are sensitive brainstem signs. Ann Neurol 33(3): 292299.

3. Bohmer A, Mast F, Jarchow T (1996) Can a unilateral loss of otolithic function be clinically detected by assessment of the subjective visual vertical? Brain Res Bull 40(5-6): 423-429.

4. Fukuda T (1959) The stepping test. Acta Otolaryngol (Stockholm) 50: 95-108.
5. Furman JM, Cass SP (1999) Benign paroxysmal positional vertigo. N Engl J Med 341(21): 1590-1596.

6. Halmagyi GM, Curthoys IS (1999) Clinical testing of otolith function. Ann NY Acad Sci 871: 221-230.

7. Benditt DG, Ferguson DW, Grubb BP, Kapoor WN, Kugler J, et al. (1996) Tilt table testing for assessing syncope. J Am Coll Cardiol 28(1): 263275.

8. Bohmer A, Mast F (1999) Assessing otolith function by the subjective visual vertical. Ann N Y Acad Sci 871: 221-231.

9. Bohmer A, Mast F (1999) Assessing otolith function by the subjective visual vertical. Ann NY Acad Sci 871: 221-230.

10. Bohmer A, Mast F (1999) Chronic unilateral loss of otolith function revealed by subjective visual vertical during off-center yaw rotation. J Vestib Res 9(6): 413-422.

11. Bonanni M, Newton R (1998) Test-retest reliability of the Fukuda stepping test. Physiother Res Int 3(1): 58-68.

12. Boniver R (2008) Head-shaking nystagmus B-ENT 4(8): 9-12

13. Burgio DL, Blakley BW, Myers SF (1991) An evaluation of the headshaking nystagmus test. Otolaryngol Head Neck Surg 105(5): 708-713.

14. Brandt T, Strupp M (2005) General vestibular testing. Clin Neurophysiol 116(2): 406-426.

15. Brignole M (2001) Task Force Report: Guidelines on Management (Diagnosis and Treatment) of Syncope. Eur Heart J vol 22(15): 12561306.

16. Cohen H, Blatchly CA, (1993) A study of the clinical test of sensory interaction and balance. Physical Therapy 73(6): 346-351.

17. Desmond Alan (2004) Vestibular Function: Evaluation and Treatment. Thieme Medical Publishers, INC, New York, USA, pp 65111.

18. (1994) Dizziness: procedure improves care for a common complaint. Mayo Clin Health Lett. December 12: 1-3.

19. Drachman DA, Hart CW (1972) An approach to the dizzy patient. Neurology 22(4): 323-334.

20. Faralli M, Manzari L, Panichi R, Botti F, Ricci G, et al. (2011) Subjective visual vertical before and after treatment of a BPPV episode. Auris Nasus Larynx 38(3): 307-311.

21. Fitzgerald B (1996) A review of the sharpened Romberg Test in diving medicine. SPUMS Journal 26(3): 142-146.

22. Friedmann G (1970) The judgment of the visual vertical and horizontal with peripheral and central vestibular lesions. Brain 93(2): 313-328.

23. Gall RM, Ireland DJ, Robertson DD (1999) Subjective visual vertical in patients with benign paroxysmal positional vertigo. J Otolaryngol 28(3): 162-165.

24. Garcia A, Jauregui-Renaud K (2003) Subjective assessment of visual verticality in follow-up of patients with vestibular disease. ENT journal 82(6): 442-446.

25. Hain T, Goebel J, Demer J, Eviatar L (2000) Assessment: vestibular testing techniques in adults and children: Report of the Therapeutics and Technology Subcommittee of the American Academy of Neurology. Neurology 55: 1431-1441.

26. Hain TC, Spindler J (1993) Head-shaking nystagmus. In Sharpe JA \& Barber HO, (eds). The vestibulo-ocular reflex and vertigo. Raven Press, New York, USA, pp. 217-28.

27. Hain TC, Fetter M, Zee DS (1987) Head-shaking nystagmus in patients with unilateral peripheral vestibular lesions. Am J Otolaryngol 8(1): 
36-47.

28. Herdman SJ (2010) Computerized dynamic visual acuity test in the assessment of vestibular deficits. In SDZ Eggers \& DS Zee (Eds.), Vertigo and imbalance: Clinical neurophysiology of the vestibular system handbook of clinical neurophysiology (vol. 9). Elsevier, Amsterdam, USA.

29. Herdman SJ, Tusa, RJ, Blatt P, Suzuki A, Venuto PJ, et al. (1998) Computerized dynamic visual acuity test in the assessment of vestibular deficits. Am J Otol 19(6): 790-796.

30. Hickey SA, Ford GR, Buckley JG, Fitzgerald O'Connor AF (1990) Unterberger stepping test: a useful indicator of peripheral vestibular dysfunction? J Laryngol Otol 104(8): 599-602.

31. Hirsch C (1940) A new labyrinthine reaction: the waltzing test. Ann Otol Rhinol Laryngol 49: 232-238.

32. Honaker Julie A, Shepard Neil T (2009) Fukuda Stepping Test Sensitivity and Specificity. Special Education and Communication Disorders Faculty Publications. Paper 20.

33. Honaker JA, Boismier TE, Shepard NP, Shepard NT (2009) Fukuda stepping test: sensitivity and specificity. J Am Acad Audiol 20(5): 311314

34. Jacobson GP, Newman CW, Kartush JM (1993) Handbook of Balance Function Testing. Singular Publishing Group, San Diego, USA.

35. Jacobson GP \& Shepard NT (Eds.), Balance function assessment and management. Plural, San Diego, CA, USA, p. 63-97.

36. Jongkee LB, Maas J, Philipszoon A (1962) Clinical nystagmography: a detailed study of electronystagmography in 341 patients with vertigo. Pract Otorhinolaryngol (Basel) 24: 65-93.

37. Jordan P (1963) Fukuda's stepping test: a preliminary report on reliability. Arch Otolaryngol 77: 243-245.

38. Lanska DJ, Goetz CG (2000) Romberg's sign: development, adoption, and adaptation in the $19^{\text {th }}$ century. Neurology 55(8): 1201-1206.

39. Lanska DJ, Remler B (1997) Benign paroxysmal positioning vertigo: classic descriptions, origins of the provocative positioning technique, and conceptual developments. Neurology 48(5): 1167-1177.

40. Lornes Parnes, Sumitk Agrawal, Jason Atlas (2003) Diagnosis and management of benign paroxysmal positional vertigo (BPPV). CMA] 169(7): 681-693.

41. Bhattacharyya N, Baugh RF, Orvidas L, Barrs D, Bronston LJ, et al. (2008) The bedside assessment of the vestibular system. Neil Bhattacharyya. Clinical practice guideline: Benign paroxysmal positional vertigo Otolaryngol Head Neck Surg 139(5 Suppl 4): S47-S81.

42. Pagarkar W, Bamiou DE, Ridout D, Luxon LM (2008) Subjective visual vertical and horizontal: effect of the preset angle. Arch Otolaryngol HNS 134(4): 394-401.

43. Pavlou, Wijnberg N, Fladon M, Bronstein A (2003) Effect of Semicircular Canal Stimulation on the Perception of the Visual Vertical. Aca Neurootology.
44. Peitersen E (1963) Vestibulospinal reflexes: acute disturbances of vestibular function after operations on the stapes, especially as evaluated by the stepping test. Acta Otolaryngol 78: 642-684.

45. Peitersen E (1964) Vestibulospinal reflexes: alterations in the stepping test in various disorders of the inner ear and vestibular nerve. Acta Otolaryngol 79: 481-486.

46. Peitersen E (1967) Vestibulospinal reflexes. X. Theoretical and clinical aspects of the stepping test. Arch Otolaryngol 85(2): 192-198.

47. Pérez P, Llorente JL, Gómez JR, Del Campo A, López A, et al. (2004) Functional significance of peripheral head-shaking nystagmus. Laryngoscope 114(6): 1078-1084.

48. Shepard NT, Telian SA (1996) Practical Management of the Balance Disorder Patient. Singular Publishing Group, San Diego, USA.

49. Tabak S, Collewijn H, Boumans LJ (1997) Deviation of the subjective vertical in long-standing unilateral vestibular loss. Acta Otolaryngologica 117(1): 1-6.

50. Tseng HZ, Chao WY (1997) Head-shaking nystagmus: a sensitive indicator of vestibular dysfunction. Clin Otolaryngol 22(6): 549-552.

51. Vereeck L, Wuyts F, Truijen S, Van de Heyning P (2008) Clinical assessment of balance: normative data and gender and age effects. Int J Audiol 47(2): 67-75.

52. Vibert D, Hausler R, Safran AB (1999) Subjective visual vertical in peripheral unilateral vestibular diseases. J VestibRes 9(2): 145-152.

53. Vibert D, Hausler R (2000) Long-term evolution of subjective visual vertical after vestibular neurectomy and labyrinthectomy. Acta Otolaryngol 120(5): 620-622.

54. Michael von Brevern, Tanja Schmidt, Uwe Schönfeld, Thomas Lempert, Andrew H Clarke (2005) Utricular dysfunction in patients with benign paroxysmal positional vertigo. Otol Neurotol 27(1): 92-96.

55. Wetzig J, Hofstetter-Degen K, Maurer J, von Baumgarten R (1992) Clinical verification of a unilateral otolith test. Acta Astronaut 27: 1924.

56. Wolfe (1993) Head-upright Tilt Test: American Fam. Physician 149158.

57. Wolf M, Hertanu T, Novikov I, Kronenberg J (1999) Epley's manoeuvre for benign paroxysmal positional vertigo: a prospective study. Clin Otolaryngol 24: 43-46.

58. Wuyts FL, Hoppenhrouwers M, Pauwels G, Van de Heyning P (2002) Unilateral otolith function testing - is the utricular function additive: J Vestib Res 11: 304.

59. Zhang YB, Wang WQ (2011) Reliability of the Fukuda stepping test to determine the side of vestibular dysfunction. J Int Med Res 39(4): 1432-1437.

60. Zwergal A, Rettinger N, Frenzel C, Dieterich M, Brandt T, et al. (2009) A bucket of static vestibular function. Neurology 72(19): 1689-1692. 
(C) Commons Attribution 4.0 License

(CC) BY DOI: $10.19080 /$ GJo.2017.05.555664
Your next submission with Juniper Publishers will reach you the below assets

- Quality Editorial service

- Swift Peer Review

- Reprints availability

- E-prints Service

- Manuscript Podcast for convenient understanding

- Global attainment for your research

- Manuscript accessibility in different formats

( Pdf, E-pub, Full Text, Audio)

- Unceasing customer service

Track the below URL for one-step submission https://juniperpublishers.com/online-submission.php 